\title{
Diffusion Dynamics of Metal Ions Uptake at the Carboxylated- Epichlorohydrin Red Onion Skin Extract Resin - Aqueous Interface
}

\author{
Millicent U. Ibezim-Ezeani*, Onyewuchi Akaranta** \\ *(Department of Department of Pure and Industrial Chemistry, University of Port Harcourt, P.M.B. 5323, \\ Choba, Port Harcourt, Nigeria. \\ ** (Department of Department of Pure and Industrial Chemistry, University of Port Harcourt, P.M.B. 5323, \\ Choba, Port Harcourt, Nigeria.
}

\begin{abstract}
Investigation into the diffusion dynamics of $\mathrm{Mn}^{2+}, \mathrm{Fe}^{2+}$ and $\mathrm{Pb}^{2+}$ ions uptake from aqueous solution by chemically modified red onion skin extract was carried out. The polyhydroxylic extract of red onion skin was utilized in the synthesis of carboxylated-epichlorohydrin red onion skin extract resin (CERR). The fourier transform infrared spectra of red onion skin extract and CERR exhibited variations in bond interactions which was ascribed to the structural modification of the extract to yield CERR. Predictions of the mechanism of diffusion dynamics were carried out by applying the data resolved from the fractional attainment of equilibrium at varied times into the Vermeulen diffusion models within the temperature range of 29 to $70^{\circ} \mathrm{C}$. The predominance of film diffusion mechanism was established from the smaller values of its diffusion coefficients as compared to those of particle diffusion. The film diffusion coefficient values were lowest at $29^{\circ} \mathrm{C}$, indicating the most probable temperature condition for optimum exchange result with the CERR. Deductions from utilizing the Arrhenius type temperature dependence equation gave negative values of activation energy $(-7.223$ $\mathrm{kJ} / \mathrm{mol}$ for $\mathrm{Mn}^{2+}$, $-6.898 \mathrm{~kJ} / \mathrm{mol}$ for $\mathrm{Fe}^{2+}$ and $-13.957 \mathrm{~kJ} / \mathrm{mol}$ for $\mathrm{Pb}^{2+}$ ions); which suggests that increase in temperature from 29 to $70^{\circ} \mathrm{C}$, lowered the rate of the exchange reaction.

Keywords: Diffusion dynamics, ion exchange resin, metal ions, red onion skin, Vermeulen diffusion models
\end{abstract}

\section{INTRODUCTION}

Diffusion is the spontaneous migration of particulate matter due to spatial gradient in concentration. The direction of the random motion of the diffusing species is down its gradient in a bid to adjust the imbalance in particle density. Thus, for a particular medium, the rate at which substances diffuse in or out of the system and its surrounding is dependent on the variability of parameters like concentration, pressure, temperature and density with change in distance and time. The dominance of diffusion and its principles have gained impetus in many technologies associated with separation, purification, redox reaction, ionic conductivity, solubility, catalysis, recrystallization, water softening, substitution, demineralization, corrosion and so on.

This paper presents the diffusion dynamics of $\mathrm{Fe}^{2+}, \mathrm{Mn}^{2+}$ and $\mathrm{Pb}^{2+}$ ions exchange at the CERR aqueous interface. Ion exchange is based on the principle of diffusion and is the stoichiometric chemical reaction in which the interchange of equivalent ions at the phase boundary is reversible [1]. Diffusion dynamics of ion exchange describes the gradient in chemical kinetics of the interchange of equivalent ions between the exchanging and exchangeable species at a given condition with time until the process attains the state of no net transfer of mass and energy at the interface.

In a given system, the steps that determine the diffusion dynamics of ion exchange process are the:

(i) Migration of exchanging ions through the bulk solution to the boundary film surrounding the surface of the resin particles.

(ii) Migration of exchanging ions from the boundary through the layer of film to the resin particles surface (film diffusion).

(iii) Migration of exchanging ions from the resin surface to the intra-particle active sites (particle diffusion).

(iv) Interchange of equivalent ions between the exchanging and the exchangeable species at the active internal surfaces of the resin particles (ion exchange).

(v) Outward migration of exchanged ions from the particle interior to the surface of the resin particles (particle diffusion).

(vi) Outward migration of exchanged ions from the resin surface to the boundary film surrounding the particles (film diffusion).

(vii) Migration of exchanged ions from the boundary film into the bulk solution. 
The steps (vii), (vi) and (v) are the reverse of steps (i), (ii) and (iii) respectively, suggesting mutual action of dominance between the film and particle diffusion mechanisms within a particular period in the exchange process. Earlier research reports emphasized that film diffusion could be ascribed the rate controlling mechanism, if uneven distribution of substance exist in the liquid film layer, coupled with prevalence of similar ionic composition throughout the exchanger. Conversely, if the concentration of ions in the exchanger is not equally proportioned, but uniformly spread within the film layer, then the condition is suggestive of particle diffusion as the rate limiting mechanism [2].

The chief interest of this investigation is to deduce the mechanism underlying the diffusion dynamics of metal ion removal with the formulated resin. The findings will form the basis for planning and modifying the process to required scale in order to achieve greater efficiency in the retrieval of metal ions from metal contaminated effluents.

\section{EXPERIMENTAL}

\subsection{Collection and Preparation of Sample}

Bulbs of red onion were sourced from the fruit garden market in Port Harcourt, Nigeria for the purpose of this investigation. The papery outer layer was peeled from the onion bulb, washed with deionised water and air dried for 3 days. The air dried skin was ground with an electric milling machine, sieved to particle size of $150 \mu \mathrm{m}$ and preserved in corked plastic container at $29^{\circ} \mathrm{C}$.

\subsection{Extraction Procedure}

The extraction of $2940 \mathrm{~g}$ of $150 \mu \mathrm{m}$ size red onion skin was performed using soxhlet extractor with acetone (BDH) as the extracting solvent. The solvent-extract mixture was transferred to rotor evaporator, and the extracted sample recovered by expelling acetone.

\subsection{Spectroscopic Studies}

The formulation of CERR was through the reaction of the extract with epichlorohydrin (Sigma Aldrich) and 4-hydroxybenzoic acid (Sigma Aldrich) [3, 4]. The characteristic functional groups present in the molecular structure of the extract and CERR samples were resolved using the Fourier Transform Infrared spectrometer (prestige 21 shimadzu) with potassium bromide pressed disc method in the frequency range of $4000-400 \mathrm{~cm}^{-1}$.

\subsection{Preparation of Standard Solutions}

The dissolution of $3.0785 \mathrm{~g}$ of $\mathrm{MnSO}_{4} \cdot \mathrm{H}_{2} \mathrm{O}$, $4.973 \mathrm{~g}$ of $\mathrm{FeSO}_{4} .7 \mathrm{H}_{2} \mathrm{O}$ and $1.59 \mathrm{~g}$ of $\mathrm{Pb}\left(\mathrm{NO}_{3}\right)_{2}$ in distilled deionised water to obtain $1000 \mathrm{mg} / \mathrm{l}$ metal ion stock solutions were each prepared in 1litre volumetric flask. All reagents used were of analytical grade. Necessary dilution of the respective stock solutions was done to obtain $50 \mathrm{mg} / \mathrm{l}$ concentration of the metal ion solution.

\subsection{Ion Exchange Study}

The batch exchange experiments were carried out by placing $1 \mathrm{~g}$ of CERR and $50 \mathrm{~cm}^{3}$ of 50 $\mathrm{mg} / \mathrm{l}$ metal $\left(\mathrm{Mn}^{2+} / \mathrm{Fe}^{2+} / \mathrm{Pb}^{2+}\right)$ ion solution into several conical flasks, then corked and shaken at the rate of 120 oscillations / min for different agitation times of 2 to $60 \mathrm{mins}$ at $29^{\circ} \mathrm{C}$. The resultant suspensions were centrifuged and filtered through glass wool. The clear filtrate was analysed using the Atomic Absorption Spectrophotometer (Perkin Elmer, Analyst 200) and the concentration of metal ion in the liquid phase was ascertained. Systematic batch experiments were conducted as described above for the metal ions at temperatures of 40,50 , 60 and $70^{\circ} \mathrm{C}$.

\section{RESULTS AND DISCUSSION}

\subsection{Spectroscopic Analysis}

The Fourier Transform Infrared of the extract and CERR were recorded at the percentage transmittance in the frequency range of $4000-400$ $\mathrm{cm}^{-1}$ and depicted in Figs. 1 and 2 respectively. The functional group assignments for the absorption bands and their possible interpretation $[5,6]$ are presented in Table 1.

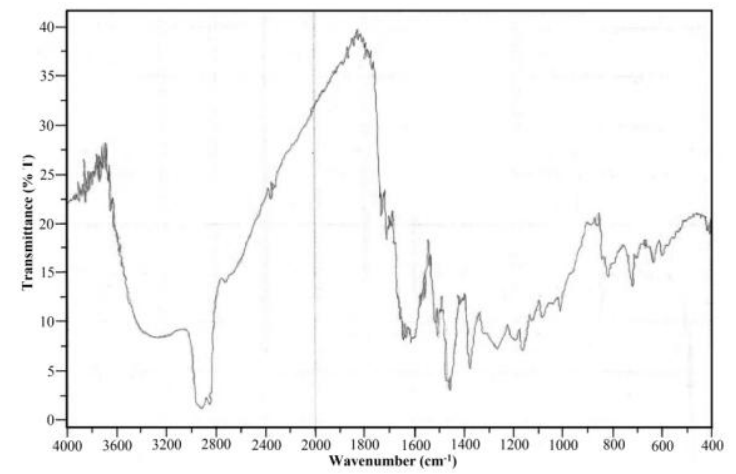

Fig. 1: Infrared Spectrum of Red Onion Skin Extract

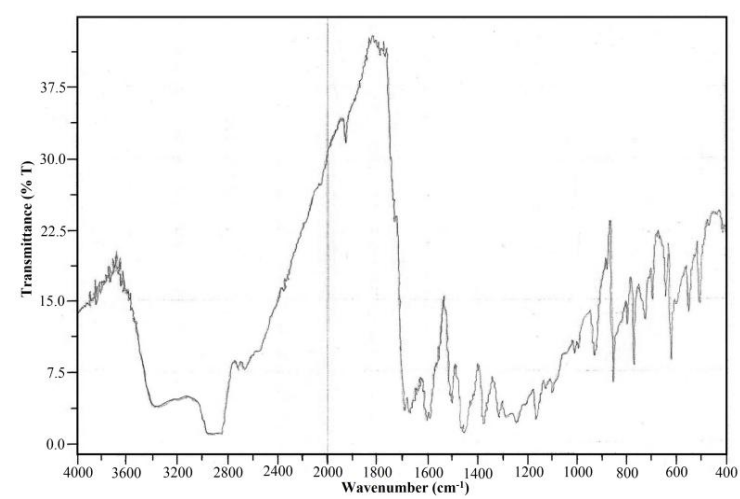

Fig. 2: Infrared Spectrum of CERR 
Spectra analyses display some differences in the absorption bands, apparently as a result of changes in the surface properties, emanating from the modification of the extract to yield CERR. The infrared spectrum of CERR (Fig. 2) showed a prominent peak at $1930 \mathrm{~cm}^{-1}$, representing weak overtone and combination of aromatic $\mathrm{C}-\mathrm{H}$ stretching bands which is characteristic of the substitution pattern of the ring. An obvious peak at $930 \mathrm{~cm}^{-1}$ in the CERR spectrum reflects the existence of intermolecular forces within the ring structure, arising from asymmetrical ring stretching in which the $\mathrm{C}-\mathrm{C}$ bond is stretching during contraction of the $\mathrm{C}-\mathrm{O}$ bond. Another pronounced peak at $495 \mathrm{~cm}^{-1}$ corresponds to C-C bending vibrations, due to bond interaction effects within the CERR molecular structure. The percentage transmittance for the infrared spectrum of the extract is relatively higher than that of CERR, indicating the influence of substitution on the structural arrangement of the CERR molecule. Further examination reveals that this difference could be related to the variation in their dipole moments [7], evidenced by changes in vibration, rotation, stretching or bending of bonds at specific frequencies of the energy in the infrared range studied. This also confirms the conversion of the extract to a new compound (CERR). The Synthesis of 4-(2,3-Epoxypropoxy) benzoic acid and proposed coupling of CERR are presented in Figs. 3 and 4 respectively.

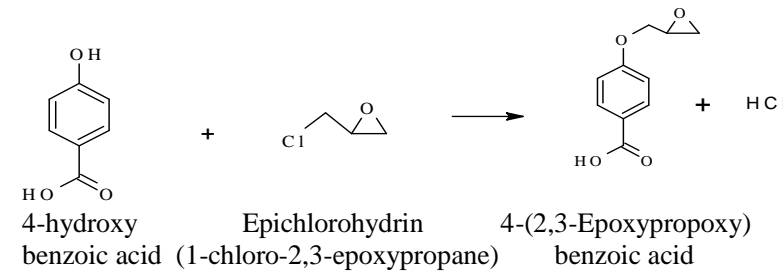

Fig. 3: Synthesis of 4-(2,3-Epoxypropoxy) benzoic acid<smiles>[R]C([R])=O</smiles>

Fig. 4: Proposed Coupling of CERR

\subsection{Diffusion Dynamics Study}

Investigation into the values of the particle and film diffusion coefficients was performed by applying the time dependent data to Vermeulen diffusion models in Eqs. (1) and (2) respectively [8]:

$$
\begin{aligned}
& -\ln \left(1-\alpha^{2}\right)=t\left(\frac{D_{p} \pi^{2}}{r_{p}^{2}}\right) \\
& -\ln (1-\alpha)=t\left(\frac{3 D_{f} C_{o}}{r_{p} \delta C_{e}}\right)
\end{aligned}
$$

$$
\alpha=\frac{C_{o}-C_{t}}{C_{o}-C_{e}}
$$

where $\alpha$ (fractional attainment of equilibrium) is the metal ion exchanged at a particular time divided by that at equilibrium (Eq. 3) [9]; $C_{o}, C_{t}$ and $C_{e}$ are the metal ion concentration initially, at time, $\mathrm{t}(\mathrm{min})$ and equilibrium (mg/l) respectively; $D_{p}$ and $D_{f}$ are diffusion coefficients $\left(\mathrm{m}^{2} / \mathrm{min}\right)$ in the ion exchanger and film respectively, $r_{p}$ is the particle radius $(m)$ and $\delta$ is the film thickness (m). The film thickness, $\delta$ can be deduced from the fringing effect in Fig. 2 using Eq. (4) [10]:

$\delta=\frac{1}{2 \mathrm{n}} \times \frac{\mathrm{N}}{\left(v_{1}-v_{2}\right)}$

where $\mathrm{n}$ is the refractive index of sample (1.362), $\mathrm{N}$ is the number of fringes within a given spectral region ( 4 in this case), $v_{1}$ and $v_{2}$ are the start and end points in the spectrum (1375 and $1165 \mathrm{~cm}^{-1}$ respectively). The plots of $-\ln \left(1-\alpha^{2}\right)$ and $-\ln (1-$ $\alpha)$ versus time at different temperatures are presented in Figs. 5 to 10.

The plots in Figs. 5 to 10 are straight lined and their $\mathrm{R}^{2}$ values are listed in Table 2 . The slope of the plots were deduced and represented as $S_{p}$ and $S_{f}$ for the particle and film diffusion respectively. Following Eqs. (1) and (2), $S_{p}$ and $S_{f}$ could be expressed as Eqs. (5) and (6) respectively:

$$
\begin{aligned}
& S_{p}=\frac{D_{p} \pi^{2}}{r_{p}^{2}} \\
& S_{f}=\frac{3 D_{f} C_{o}}{r_{p} \delta C_{e}}
\end{aligned}
$$

The $D_{f}$ and $D_{p}$ are then made the subject of the formula in Eqs. (7) and (8) respectively. The values of $D_{f}$ and $D_{p}$ computed at temperatures of 29 to $70^{\circ} \mathrm{C}$ are presented in Table 2 for the metal ions.

$D_{p}=\frac{S_{p} r_{p}^{2}}{\pi^{2}}$

$D_{f}=\frac{S_{f} \delta C_{e} r_{p}}{3 C_{o}}$

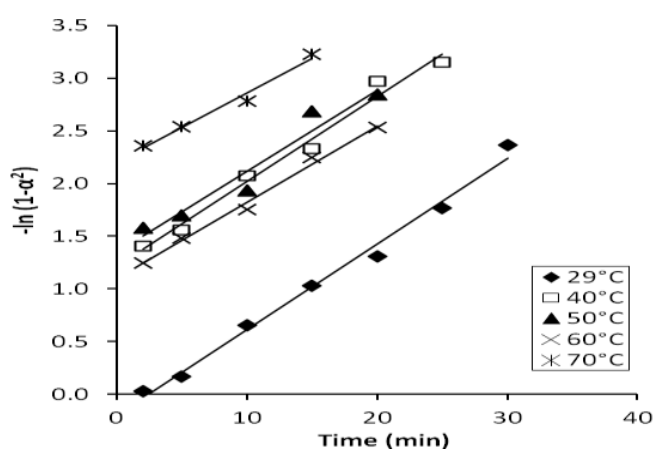

Fig. 5: Vermeulen particle diffusion model isotherms for $\mathrm{Mn}^{2+}$ ion 


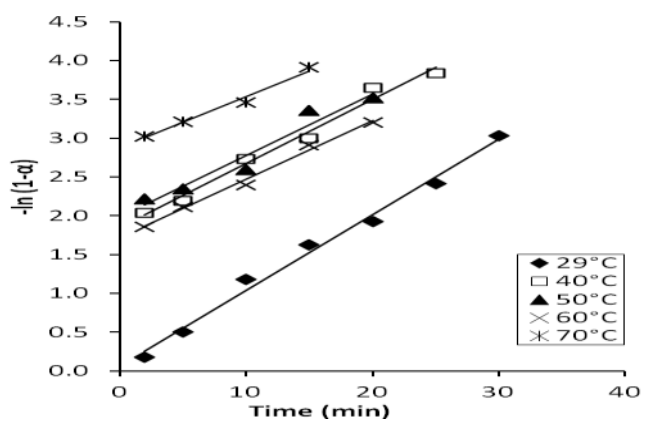

Fig. 6: Vermeulen film diffusion model isotherms for $\mathrm{Mn}^{2+}$ ion

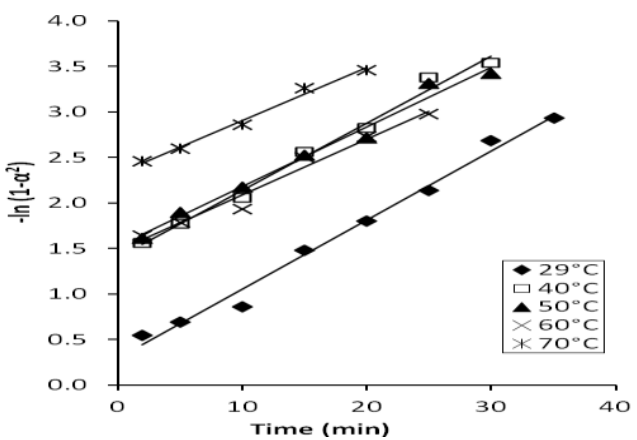

Fig. 7: Vermeulen particle diffusion model isotherms for $\mathrm{Fe}^{2+}$ ion

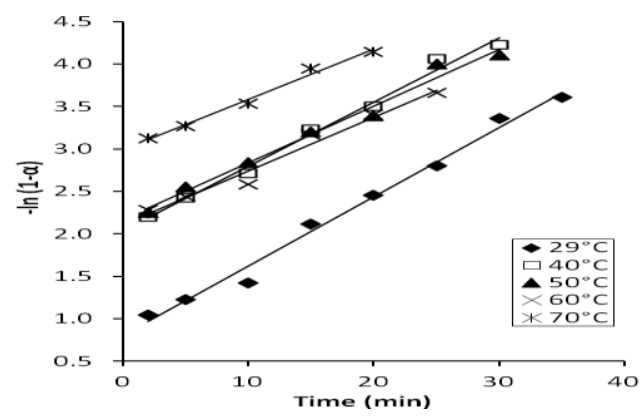

Fig. 8: Vermeulen film diffusion model isotherms for $\mathrm{Fe}^{2+}$ ion

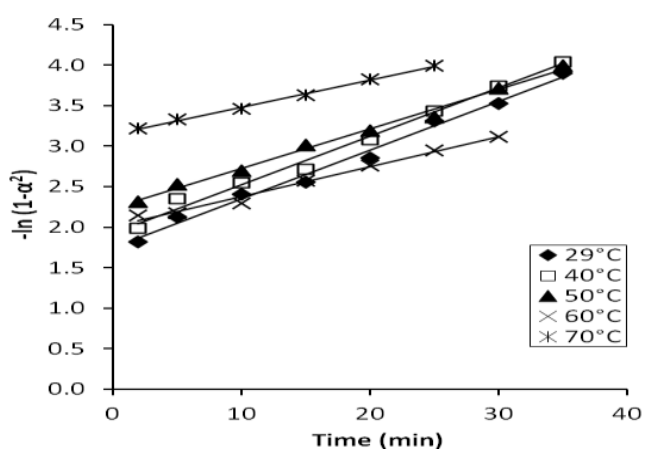

Fig. 9: Vermeulen particle diffusion model isotherms for $\mathrm{Pb}^{2+}$ ion

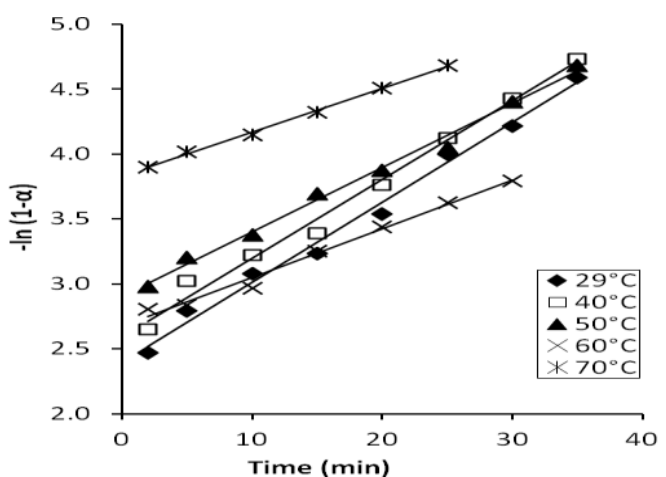

Fig. 10: Vermeulen film diffusion model isotherms for $\mathrm{Pb}^{2+}$ ion

Data analyses show that the values of the film diffusion coefficient range from $4.551 \times 10^{-11}$ $1.229 \times 10^{-10} \mathrm{~m}^{2} / \mathrm{min}\left(7.86 \times 10^{-7}-4.58 \times 10^{-6} \mathrm{~cm}^{2} / \mathrm{s}\right)$ for $\mathrm{Mn}^{2+}, 6.566 \times 10^{-11}-1.189 \times 10^{-10} \mathrm{~m}^{2} / \mathrm{min}(1.62$ $-5.61 \times 10^{-6} \mathrm{~cm}^{2} / \mathrm{s}$ ) for $\mathrm{Fe}^{2+}$ and $7.227 \times 10^{-11}$ $7.868 \times 10^{-11} \mathrm{~m}^{2} / \mathrm{min}\left(3.17-11.53 \times 10^{-6} \mathrm{~cm}^{2} / \mathrm{s}\right)$ for $\mathrm{Pb}^{2+}$ ions; while that of particle diffusion is from $1.852 \times 10^{-10}-1.483 \times 10^{-10} \mathrm{~m}^{2} / \mathrm{min}(4.63-5.72 \times$ $\left.10^{-6} \mathrm{~cm}^{2} / \mathrm{s}\right)$ for $\mathrm{Mn}^{2+}, 1.736 \times 10^{-10}-1.328 \times 10^{-10}$ $\mathrm{m}^{2} / \mathrm{min}\left(4.93-6.44 \times 10^{-6} \mathrm{~cm}^{2} / \mathrm{s}\right)$ for $\mathrm{Fe}^{2+}$ and 1.373 x $10^{-10}-7.607 \times 10^{-11} \mathrm{~m}^{2} / \mathrm{min}\left(6.23 \times 10^{-6}-1.13 \mathrm{x}\right.$ $10^{-5} \mathrm{~cm}^{2} / \mathrm{s}$ ) for $\mathrm{Pb}^{2+}$ ions. These values infer that the limiting mechanism for metal ions uptake rate is film diffusion, since the values of $\mathrm{D}_{\mathrm{f}}$ are lower than those of $D_{p}$. Research on the rate of ammonium uptake by natural zeolite and transcarpathian mordenite reported $0.7-3.6 \times 10^{-12} \mathrm{~m}^{2} / \mathrm{s}$ and $1.26-9.73 \times 10^{-12}$ $\mathrm{m}^{2} / \mathrm{s}$ range of coefficient values for particle diffusion and film diffusion respectively. The research team remarked that the ion exchange reaction was dominated by the model of particle diffusion and ascribed their findings to the influence of structural feature of the mordenite mineral fraction on the process [8]. Vinod and Anirudhan studied tannic acid sorption on zirconium pillared clay; and reported values within $10^{-9} \mathrm{~cm}^{2} / \mathrm{s}$ and $10^{-7} \mathrm{~cm}^{2} / \mathrm{s}$ for $D_{p}$ and $D_{f}$ respectively. They hinted that the process is not purely film diffusion controlled but involves particle diffusion in the latter stages [11]. The diffusivity values deduced in the biosorption of $\mathrm{Cr}$ (VI) ion by Aeromonas cavie decreased with increase in temperature from 20 to $60{ }^{\circ} \mathrm{C}$, apparently due to the modification of surface geometry of the biomass at elevated temperatures [12].

Also, the values of coefficient of determination $\left(\mathrm{R}^{2}\right)$ within the temperature range (Table 2) tested reflects a little difference between that of film and particle diffusion models, suggesting a complementary relationship between their mechanisms. However, the higher $\mathrm{R}^{2}$ values for the film diffusion mechanism in all cases, is an evidence of its superior influence over that of particle diffusion on the exchange process. 
The relationship that correlates the time dependence of the fractional attainment of equilibrium, $\alpha$ is given in Eq. (9) [13]. The plots of $\ln (1-\alpha)$ against time are depicted in Figures 11,12 and 13 for $\mathrm{Mn}^{2+}, \mathrm{Fe}^{2+}$ and $\mathrm{Pb}^{2+}$ respectively.

$\ln (1-\alpha)=-k t$

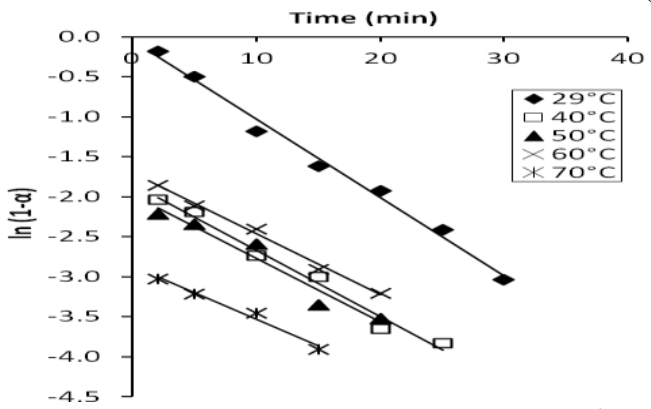

Fig. 11: Plot of $\ln (1-\alpha)$ against time for $\mathrm{Mn}^{2+}$ ion

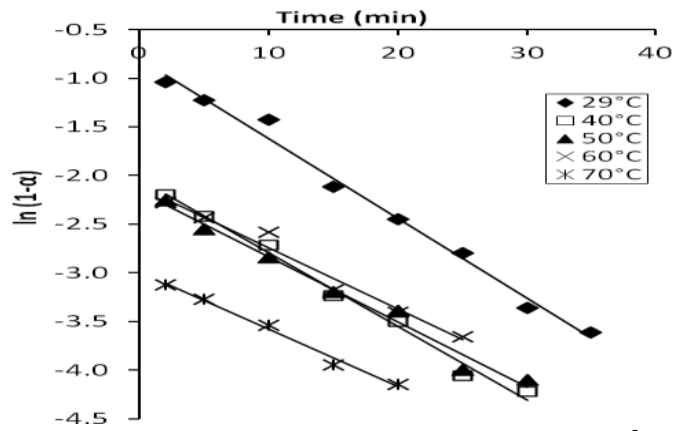

Fig. 12: Plot of $\ln (1-\alpha)$ against time for $\mathrm{Fe}^{2+}$ ion

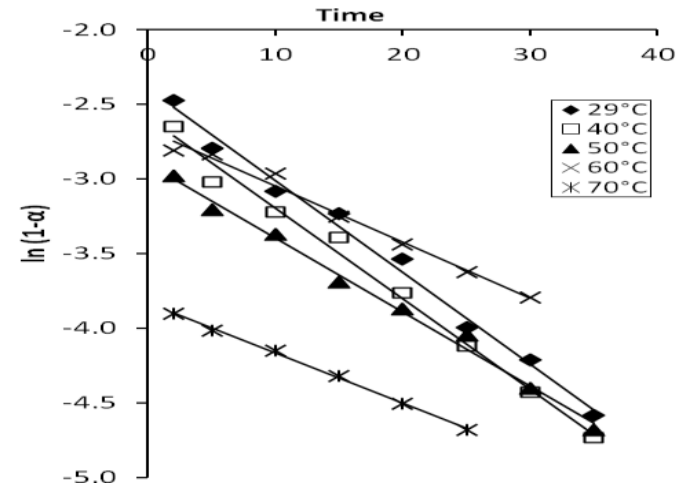

Fig. 13: Plot of $\ln (1-\alpha)$ against time for $\mathrm{Pb}^{2+}$ ion

The reaction rate constants $(\mathrm{k})$ at different temperatures were extrapolated from the slope of the straight line plots of $\ln (1-\alpha)$ against time and the values presented in Table 2 . The values of $\mathrm{k}$ decreased in the order: $29>40>50>60>70{ }^{\circ} \mathrm{C}$, indicating that the rate of reaction is highest at $29^{\circ} \mathrm{C}$ within the temperature range tested.

The temperature dependence of ion exchange rates was demonstrated by the linear behavior of the plot of $\ln \mathrm{k}$ versus $1 / \mathrm{T}$ (Fig. 14) using the Arrhenius expression [14,15] in Eq. (10):

$\ln k=\ln A-\frac{E a}{R T}$

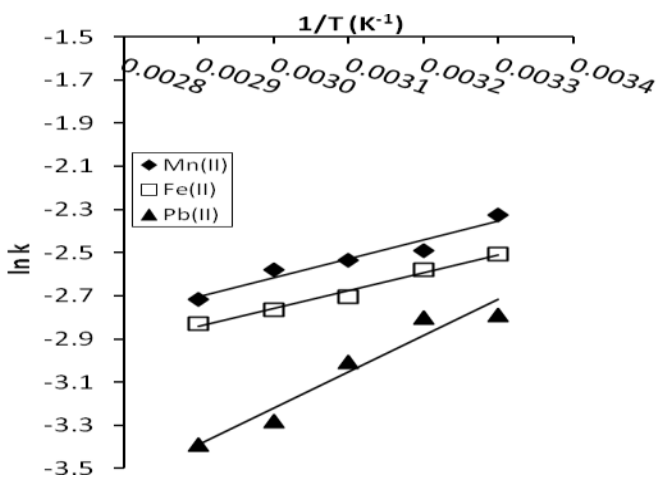

Fig. 14: Arrhenius plots for the metal ions

where $\mathrm{A}, \mathrm{Ea}, \mathrm{R}$ and $\mathrm{T}$ are the pre-exponential factor, activation energy, gas constant and temperature respectively. The values of Ea and A were computed from the slope and intercept of the plots, and presented in Table 3. The Ea values represent the lowest amount of kinetic energy which is sufficient for effective interaction between the exchanging and exchangeable species in the systematic uptake of the metal ions.

Table 3: Kinetic parameters for the exchange process with CERR

\begin{tabular}{|c|c|c|c|}
\hline $\begin{array}{c}\text { Metal } \\
\text { ion }\end{array}$ & Linear equation & $\begin{array}{c}\mathbf{A} \\
{\left[\mathrm{min}^{-1}\right]}\end{array}$ & $\begin{array}{c}\text { Ea } \\
{[\mathrm{kJ} / \mathrm{mol}]}\end{array}$ \\
\hline $\mathrm{Mn}^{2+}$ & $\mathrm{y}=868.8 \mathrm{x}-5.222$ & $5.395 \times 10^{-3}$ & -7.223 \\
\hline $\mathrm{Fe}^{2+}$ & $\mathrm{y}=829.7 \mathrm{x}-5.248$ & $5.257 \times 10^{-3}$ & -6.898 \\
\hline $\mathrm{Pb}^{2+}$ & $\mathrm{y}=1678.0 \mathrm{x}-8.258$ & $2.592 \times 10^{-4}$ & -13.957 \\
\hline
\end{tabular}

If the value of $\mathrm{Ea}$ is positive, it signifies that the rate constant is strongly temperature dependent; If Ea is zero, its rate is not dependent on temperature and if Ea is negative, it indicates that the rate is inversely proportional to temperature [16].The negative values of Ea deduced in this study, therefore suggest that the exchange rate is most favored at $29{ }^{\circ} \mathrm{C}$ within the experimental temperatures. The pre-exponential factor incorporates the frequency of molecular collision and geometric requirement for the orientation of the colliding molecules of the reactants [17]. The calculated values of $\mathrm{A}$ are in the order: $\mathrm{Mn}^{2+}>\mathrm{Fe}^{2+}$ $>\mathrm{Pb}^{2+}$, which is in line with that of their ionic radii. This indicates that the smaller the metal ionic size, the more enhanced its diffusion to the active site with time, and the higher the probability of its proper spatial positioning to produce useful molecular impact at the moment of contact.

\section{CONCLUSION}

The extract of red onion skin (a biodegradable agro waste) has been applied in the synthesis of cation exchange resin for the uptake of $\mathrm{Mn}^{2+}, \mathrm{Fe}^{2+}$ and $\mathrm{Pb}^{2+}$ ions from aqueous medium. The infrared spectroscopic examination of the red onion skin extract and CERR in the frequency range of 
4000 to $400 \mathrm{~cm}^{-1}$ revealed some differences in their absorption bands, possibly due to the successful modification of extract to yield a new compound (CERR). The Vermeulen diffusion equations were used to study the diffusion dynamics of the exchange process at temperatures of 29 to $70{ }^{\circ} \mathrm{C}$. The film diffusion exhibited smaller values of diffusion coefficients as compared to those of particle

\section{ACKNOWLEDGEMENTS}

Special thanks to Prof. Raphael Ngochindo (Department of Pure and Industrial Chemistry, University of Port Harcourt, Rivers State, Nigeria) for supporting this work with useful suggestions. We also appreciate Miss Kate Iwunor (FUGRO Ltd, Eleme, Rivers State, Nigeria) for the spectrophotometric analyses.

\section{REFERENCES}

[1]. M. U. Ibezim-Ezeani, F. A. Okoye, O. Akaranta, Int. J.Water Res. Environ. Eng., 4 (6) (2012) 192-200.

[2]. A. Jignasa, R. Thakkar, C. Uma, J. Chem. Sci., 118 (2) (2006) 185-189.

[3]. M. U. Ibezim-Ezeani, A. F. Okon, Res. J. Chem. Sci., 6 (9) (2016) 49-54.

[4]. M. U. Ibezim-Ezeani, O. Akaranta, Int. J. ChemTech Res., 9 (9) (2016) 550-562.

[5]. B. A. Uzoukwu, Basic Analytical Chemistry, millennium ed., Paragraphics, Port Harcourt, Nigeria, 2009.

[6]. R. M. Silverstein, G. C. Bassier, T. C. Morrill, Spectrometric Identification of Organic Compounds, 5th ed., John Wiley and Sons, Inc., USA, 1991.

[7]. C. L. Beh, T. G. Chuah, M. N. Nourouzi, T. S. Y. Choong, E-J. Chemistry, 9 (4) (2012) 2557- 2564. diffusion, and was therefore considered as the rate controlling mechanism. Application of the rate constants evaluated at temperatures of 29, 40, 50, 60 and $70{ }^{\circ} \mathrm{C}$ to the Arrhenius equation, resulted in $\mathrm{Ea}$ with negative values indicating that the exchange process is more favored at $29^{\circ} \mathrm{C}$.

[8]. M. Sprynskyy, M. Lebedynets, R. Zbytniewski, J. Namieśnik, B. Buszewski, Separation Purification Technol., 46 (2005) 155-160.

[9]. M. Sekar, V. Sakthi, S. Rengaraji, J. Colloid Interface Sci., 279 (2004) 307-313.

[10]. Pike Technologies Spectroscopic Creativity, Calculating the thickness of free - standing Films by FTIR, Application Note - 0502, www.piketech.com (accessed $12^{\text {th }}$ June, 2016)

[11]. V. P. Vinod, T. S. Anirudhan, J. Chem. Technol. Biotechnol., 77 (2001) 92-101.

[12]. M. X. Loukidou, D. K. Thodoris, A. L. Zouboulis, K. A. Matis, Ind. Eng. Chem. Res., 43 (2004) 1748-1755.

[13]. G. Karthikeyan, K. Anbalagan, N. M. Andal, J. Chem. Sci., 116 (2) (2004) 119-127.

[14]. M. U. Ibezim-Ezeani, A. C. I. Anusiem, Int. J. Phys. Sci., 5 (9) (2010) 62-67.

[15]. D. Kaušpèdienè, E. Kazlauskiene, A. Selskiene, Ion Exchange Letters, 3 (2010) 1924.

[16]. P. W. Atkins, Physical Chemistry, 6th ed., Oxford University Press, New York, 1998.

[17]. A. C. I. Anusiem, Principles of General Chemistry, revised ed., Versatile Publishers, Owerri, Nigeria, 2000.

Table 1: Infrared absorption bands and their functional group assignments

\begin{tabular}{|c|c|c|c|}
\hline \multicolumn{2}{|c|}{ Absorption bands $\left[\mathrm{cm}^{-1}\right]$} & \multirow{2}{*}{$\begin{array}{l}\text { Functional } \\
\text { group } \\
\text { assignments }\end{array}$} & \multirow{2}{*}{ Possible interpretation } \\
\hline Extract & Resin & & \\
\hline $\begin{array}{c}3400- \\
3250\end{array}$ & $3400-3300$ & $\mathrm{O}-\mathrm{H}$ & $\begin{array}{l}\text { Broad band attributed to the } \mathrm{O}-\mathrm{H} \text { stretching of } \\
\text { intermolecular hydrogen bonded hydroxyl groups }\end{array}$ \\
\hline \multirow[t]{2}{*}{$\begin{array}{l}2950- \\
2825\end{array}$} & $\begin{array}{l}2970-2850 \\
2660\end{array}$ & $\mathrm{C}-\mathrm{H}$ & $\begin{array}{l}\text { Absorption bands indicate the presence of C-H } \\
\text { stretching }\end{array}$ \\
\hline & 1930 & $\mathrm{C}-\mathrm{H}$ & $\begin{array}{l}\text { Weak combination and overtone bands of aromatic } \\
\mathrm{C}-\mathrm{H} \text { stretching appear in the } 2000-1650 \mathrm{~cm}^{-1} \\
\text { region }\end{array}$ \\
\hline $\begin{array}{c}1725, \\
1715,1660\end{array}$ & 1690 & $\mathrm{C}=\mathrm{O}$ & $\begin{array}{l}\text { Absorption peaks in the } \mathrm{C}=\mathrm{O} \text { stretching region of } \\
\text { carboxylic acids and ketones }\end{array}$ \\
\hline $\begin{array}{c}1590 \\
1505,1460\end{array}$ & $\begin{array}{l}1600,1500 \\
1460\end{array}$ & $\mathrm{C}=\mathrm{C}$ & $\begin{array}{l}\text { Skeletal vibrations involving } C=C \text { stretching } \\
\text { within the ring, absorb in the } 1600-1585 \text { and } \\
1500-1400 \mathrm{~cm}^{-1} \text { region }\end{array}$ \\
\hline 1370 & 1375 & $\mathrm{C}-\mathrm{O}$ & $\begin{array}{l}\text { Mulls, pellets or melts of phenols absorb at } 1390- \\
1330 \text { and } 1260-1180 \mathrm{~cm}^{-1} \text { bands, apparently } \\
\text { resulting from interaction between O-H bending }\end{array}$ \\
\hline
\end{tabular}


1270 ,

1160,1020

$$
1320,1290 \text {, }
$$

1245 ,

1165,1100

$\mathrm{C}-\mathrm{O}$

$930 \quad$ C-C

$\begin{array}{ccc}820,720 & 860,765, & \mathrm{C}-\mathrm{H}\end{array}$

$635,605 \quad 650,620,550 \quad \mathrm{C}-\mathrm{Br}$

$495 \quad$ C-C and $\mathrm{C}-\mathrm{O}$ stretching. Also $\mathrm{O}-\mathrm{H}$ in - plane bending vibration occurs in the general region of 1420 $1330 \mathrm{~cm}^{-1}$

These wave numbers are in the $\mathrm{C}-\mathrm{O}$ stretching region $\left(1300-1050 \mathrm{~cm}^{-1}\right)$ of alcohols, carboxylic acids and ethers

Band appearing in the $950-810 \mathrm{~cm}^{-1}$ region is attributed to asymmetrical ring stretching in which the $\mathrm{C}-\mathrm{C}$ bond is stretching during contraction of the $\mathrm{C}-\mathrm{O}$ bond

The most characteristic absorption of polynuclear aromatics results from $\mathrm{C}-\mathrm{H}$ out-of-plane ring bending in the $900-675 \mathrm{~cm}^{-1}$ region

Brominated compounds absorb in the $690-515$ $\mathrm{cm}^{-1}$ region

The $\mathrm{C}-\mathrm{C}$ bending vibrations occur at frequencies below $500 \mathrm{~cm}^{-1}$ region

Table 2: Coefficients of determination $\left(\mathrm{R}^{2}\right)$ and parameters for the diffusion dynamics

\begin{tabular}{|c|c|c|c|c|c|c|c|c|}
\hline \multirow{2}{*}{$\begin{array}{l}\text { Metal } \\
\text { Ion }\end{array}$} & \multirow{2}{*}{$\begin{array}{c}\text { Temp } \\
{\left[{ }^{\circ} \mathrm{C}\right]}\end{array}$} & \multirow{2}{*}{$\underset{\left[\mathrm{min}^{-1}\right]}{\mathbf{k}}$} & \multicolumn{3}{|c|}{ Film diffusion $[-\ln (1-\alpha)]$} & \multicolumn{3}{|c|}{ Particle diffusion $\left[-\ln \left(1-\alpha^{2}\right)\right]$} \\
\hline & & & $\mathrm{R}^{2}$ & Regression Equation & $\mathrm{D}_{\mathrm{f}}\left[\mathrm{m}^{2} \mathrm{~min}^{-1}\right]$ & $\mathrm{R}^{2}$ & Regression Equation & $\mathrm{D}_{\mathrm{p}}\left[\mathrm{m}^{2} \mathrm{~min}^{-1}\right]$ \\
\hline \multirow{5}{*}{$\mathrm{Mn}^{2+}$} & 29 & 0.0978 & 0.9909 & $y=0.0978 x+0.0555$ & $4.551 \times 10^{-11}$ & 0.9902 & $y=0.0813 x-0.1959$ & $1.852 \times 10^{-10}$ \\
\hline & 40 & 0.0828 & 0.9832 & $y=0.0828 x+1.8457$ & $5.999 \times 10^{-11}$ & 0.9831 & $y=0.0802 x+1.2198$ & $1.827 \times 10^{-10}$ \\
\hline & 50 & 0.0794 & 0.9454 & $y=0.0794 x+1.9817$ & $7.486 \times 10^{-11}$ & 0.9444 & $y=0.0769 x+1.3493$ & $1.752 \times 10^{-10}$ \\
\hline & 60 & 0.0758 & 0.9920 & $y=0.0758 x+1.7095$ & $1.062 \times 10^{-10}$ & 0.9918 & $y=0.0725 x+1.0987$ & $1.651 \times 10^{-10}$ \\
\hline & 70 & 0.0662 & 0.9806 & $y=0.0662 x+2.8728$ & $1.229 \times 10^{-10}$ & 0.9801 & $y=0.0651 x+2.2060$ & $1.483 \times 10^{-10}$ \\
\hline \multirow{5}{*}{$\mathrm{Fe}^{2+}$} & 29 & 0.0817 & 0.9897 & $y=0.0817 x+0.8017$ & $6.566 \times 10^{-11}$ & 0.9885 & $y=0.0762 x+0.2887$ & $1.736 \times 10^{-10}$ \\
\hline & 40 & 0.0757 & 0.9901 & $y=0.0757 x+2.0362$ & $7.170 \times 10^{-11}$ & 0.9900 & $9 x+1.3970$ & $1.683 \times 10^{-10}$ \\
\hline & 50 & 0.0670 & 0.9837 & $y=0.0670 x+2.1661$ & $8.259 \times 10^{-11}$ & 0.9836 & $y=0.0655 x+1.5222$ & $1.492 \times 10^{-10}$ \\
\hline & 60 & 0.0631 & 0.9938 & $y=0.0631 x+2.1124$ & $1.008 \times 10^{-10}$ & 0.9937 & $y=0.0613 x+1.4735$ & $1.396 \times 10^{-10}$ \\
\hline & 70 & 0.0591 & 0.9896 & $y=0.0591 x+2.9892$ & $1.189 \times 10^{-10}$ & 0.9895 & $y=0.0583 x+2.3193$ & $1.328 \times 10^{-10}$ \\
\hline \multirow{5}{*}{$\mathrm{Pb}^{2+}$} & 29 & 0.0614 & 0.9903 & $y=0.0614 x+2.3993$ & $7.227 \times 10^{-11}$ & 0.9902 & $y=0.0603 x+1.7440$ & $1.373 \times 10^{-10}$ \\
\hline & 40 & 0.0607 & 0.9902 & $y=0.0607 x+2.5890$ & $8.169 \times 10^{-11}$ & 0.9901 & $y=0.0598 x+1.9272$ & $1.362 \times 10^{-10}$ \\
\hline & 50 & 0.0495 & 0.9927 & $y=0.0495 x+2.9030$ & $8.036 \times 10^{-11}$ & 0.9925 & $y=0.0489 x+2.2338$ & $1.114 \times 10^{-10}$ \\
\hline & 60 & 0.0376 & 0.9875 & $y=0.0376 x+2.6707$ & $7.271 \times 10^{-11}$ & 0.9874 & $y=0.0368 x+2.0100$ & $8.382 \times 10^{-11}$ \\
\hline & 70 & 0.0337 & 0.9980 & $y=0.0337 x+3.8301$ & $7.868 \times 10^{-11}$ & 0.9979 & $y=0.0334 x+3.1473$ & $7.607 \times 10^{-11}$ \\
\hline
\end{tabular}

